\title{
A clinicopathological study and management of odontogenic keratocyst
}

\author{
Dr. Mohammad Asifur Rahman ${ }^{1 *}$, Dr. Tarin Rahman², Dr. Ismat Ara Haider ${ }^{3}$
}

\section{AFFILIATION:}

1. Dr.Mohammad Asifur Rahman, BDS, MS(OMS), Assistant Professor, Department of Oral \& Maxillofacial Surgery, Dhaka Dental College \& Hospital, Dhaka.

2. Dr. Tarin Rahman, BDS, MS (OMS), Associate Professor, Department of Oral \& Maxillofacial Surgery, Dhaka Dental College \& Hospital, Dhaka.

3. Dr. Ismat Ara Haider, BDS, DDS, MS (OMS),

Professor \& Head

Department of Oral \& Maxillofacial Surgery, Dhaka Dental College \& Hospital, Dhaka.

\section{Article info.}

Received: $20^{\text {th }}$ October, 2018

Accepted: $15^{\text {th }}$ December, 2018

Volume: 9, Issue-1 April, 2019

DOI: https://doi.org/10.3329/updcj.v9i1.41200

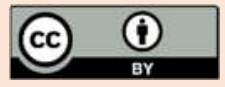

(C) Authors retain copyright and grant the journal right of first publication with the work simultaneously licensed under Creative Commons Attribution License CC - BY 4.0 that allows others to share the work with an acknowledgment of the work's authorship and initial publication in this journal.

https://creativecommons.org/licenses/by/4.0/

Publisher: Update Dental College, Dhaka, Bangladesh

Web: www.updatedentalcollege.edu.bd

E-mail: updcj@hotmail.com

\author{
* Corresponding Author \\ Dr. Mohammad Asifur Rahman \\ BDS, MS (OMS) \\ Assistant professor, \\ Department of Oral \& Maxillofacial Surgery, \\ Dhaka Dental College \& Hospital, Dhaka. \\ E-mail: asif.omfs@gmail.com
}

\section{Citation}

Dr. Mohammad Asifur Rahman, Dr. Tarin Rahman, Dr. Ismat Ara Haider. A clinicopathological study and management of odontogenic keratocyst. Update Dental College Journal. 2019 April; 9(1): 8-15

DOI: https://doi.org/10.3329/updcj.v9i1.41200

\begin{abstract}
Odontogenic Keratocyst is an aggressive odontogenic cyst with a high recurrence rate. After radicular and follicular cysts, odontogenic keratocysts are the third most common cyst of the jaws and approximately $12-14 \%$ of all odontogenic cysts. It has been retermed to Keratocystic odontogenic tumour (KCOT) as it better reflects its neoplastic nature but recently it has been re classified and retermed into the cystic category. Various surgical methods have been proposed but comparatively, conservative treatment options such as Dredging methods might be the treatment of choice due to preservation of anatomical structure.

Objective: The aim of this study was to analyse the clinical, radiological and histopathological characteristics of Odontogenic Keratocyst and provide a proper management system affected by this type of lesions.
\end{abstract}

Materials and methods: The prospective study was performed in Dhaka Dental College and Hospital from a period of January 2014 to January 2018. A total number of 75 patients were selected for this study based on clinical, radiological and histopathological confirmation of odontogenic keratocysts. The treatment options were enucleation, enucleation with curettage, enucleation with peripheral ostectomy, Dredging method and surgical resection. After treatment patients were followed up 1 months, 3 months and 6 months in every year at least for 5 years.

Results: Among 75 patient of odontogenic keratocyst; the mean age was $27.69 \pm 13.35$ and age range was 11 to 66 years. Male were $53(71 \%)$ and 22 $(29 \%)$ were female patients. $53(70.67 \%)$ cases were found in the mandible, $15(20 \%)$ cases in the maxilla and in $7(9.33 \%)$ cases were involved in both maxilla and mandible; mandibular posterior region was the most specific region involved $37(69.81 \%)$. The most common clinical features revealed pain and swelling. Radiologically, $70.66 \%$ unilocular, $96 \%$ well defined and $94.66 \%$ radiolucent area were prominent. Bone expansion $37.38 \%$, root resorption $30.00 \%$ and $36 \%$ were associated with an impacted tooth. Regarding treatment options enucleation with curatage $12 \%$, enucleation, curettage \& peripheral ostectomy $29.33 \%$, Dredging $52 \%$ and surgical resection $6.6 \%$ was done. Recurrence occurred in 18 patients with recurrence rate of $24 \%$.

Conclusion: Odontogenic keratocyst is an aggressive cyst, male predominant, posterior mandible is the commonest site and well defined unilocular radiolucency are commonest radiological feature. Radical treatment options such as resection reduced the recurrences of the tumour but higher morbidity and jaw deformity. Comparatively, conservative treatment options such as Dredging methods might be the treatment of choice due to preservation of anatomical structure. A long term follow up is paramount importance for the research and understanding the clinical pattern, behavior, treatment and recurrence of the lesion.

\section{KEY WORDS}

Odontogenic Keratocyst, Clinicopathological study, Treatment modalities, Recurrences 


\section{Introduction}

Odontogenic Keratocyst (OKC) is an aggressive odontogenic cyst arising from dental lamina and is unique for its innate growth potential like tumours with an aggressive clinical patterns and association with high recurrence rate. ${ }^{1}$ After radicular and follicular cysts, odontogenic keratocysts are the third most common cyst ${ }^{2}$ and approximately $12-14 \%$ of all odontogenic cysts of jaws. ${ }^{3}$ It has been retermed to Keratocystic odontogenic tumour (KCOT) as it better reflects its aggressive behavior, high recurrence rate and neoplastic nature but recently it has been re classified and retermed into the cystic category by WHO 2017 classification. ${ }^{4}$

Two histologic variants has been classified - orthokeratinized or parakeratinized. The orthokeratinized variant not only lacks of the typical characteristics of the parakeratinized one but also has different biological characteristics and consequently a much lower recurrence rate. ${ }^{2}$

Various treatment modalities have been published in literature for odontogenic keratocyst but the universally accepted approach remains undecided. Treatment generally includes from conservative methods such as marsupialization, enucleation, curettage, chemical cauterization, peripheral ostectomy to much aggressive treatments such as marginal or segmental resection. ${ }^{5}$ However, no good evidence is currently available regarding the best treatment option.

In this article, we analysis and share our experience in the clinical, radiological and histopathological characteristics of odontogenic keratocyst and provide a proper management system affected by this type of lesions.

\section{Materials and methods}

The prospective study was performed in Department of Oral \& Maxillofacial Surgery, Dhaka Dental College and Hospital, Dhaka, Bangladesh from a period of January 2014 to January 2018.

The study population was divided into two groups, according to the clinical and diagnostic criteria. The first group comprised symptomatic cases with clinical findings like pain, swelling. The second group included asymptomatic cases, with the diagnosis made incidentally by radiographic findings or during routine dental examination.

The location of the cyst was divided into mandible and maxilla. In the maxilla either in anterior (incisor and canine) or posterior (premolar and molar) regions and in the mandible it was divided into anterior (symphysis, para symphysis) and posterior regions (body, angle, ramus, condyle and coronoid process). Radiographical findings were recorded as well defined, ill defined, unilocular or multilocular, radiolucent or radioopaque lesions with single or multiple location. Information was also recorded about whether a tooth was related with the lesion, displacement of adjacent teeth with or without root resorption, impacted tooth, expansion of cortical plates with or without perforation. Histological findings were also recorded either it was orthokeratinised, parakeratinised or both type of lesions.

The treatment options in this study were enucleation, enucleation of the cyst with curettage and peripheral ostectomy, Dredging method and surgical resection and reconstruction in all cases. The specimen was sent for histopathological examination and a diagnosis of odontogenic keratocyst was confirmed. Patients were regular follow up after 1 months, 3 months and 6 months in every year at least for 5 years. Any complication during the treatment or the follow-up period, the incidence and the time of recurrence and management were also recorded.

Result:

Table 1: Age distribution of the patients. $(n-75)$

\begin{tabular}{|l|l|l|}
\hline Age & Frequency & Percentage \\
\hline & & \\
\hline $0-10$ & 00 & 00 \\
\hline $11-20$ & 26 & 34.7 \\
\hline $21-30$ & 25 & 33.3 \\
\hline $31-40$ & 11 & 14.7 \\
\hline $41-50$ & 07 & 9.3 \\
\hline $51-60$ & 04 & 5.3 \\
\hline $61-70$ & 02 & 2.7 \\
\hline Total & 75 & 100.0 \\
\hline Mean ( \pm SD) & $27.69 \pm 13.35$ & \\
\hline Range & $(11-66)$ years & \\
\hline
\end{tabular}

The study included a total of 75 patients. The age of the patients ranged from 11 to 66 years, with a peak incidence in the second and third decade of life (26) cases (34.7\%) and (25) cases (33.3\%). The mean age was $(29.2 \%)$ $27.69 \pm 13.35$ years.

Figure 1: Sex distribution of the patients. $(n-75)$

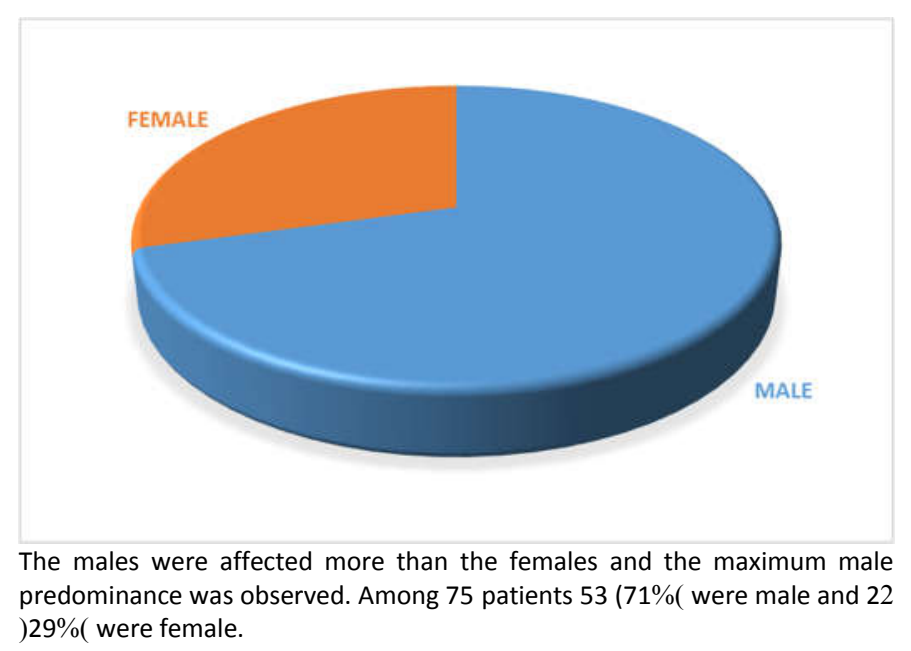

Website: https://www.banglajol.info/index.php/UpDCJ 
Figure 2: Clinical manifestation of odontogenic keratocyst (n - 75)

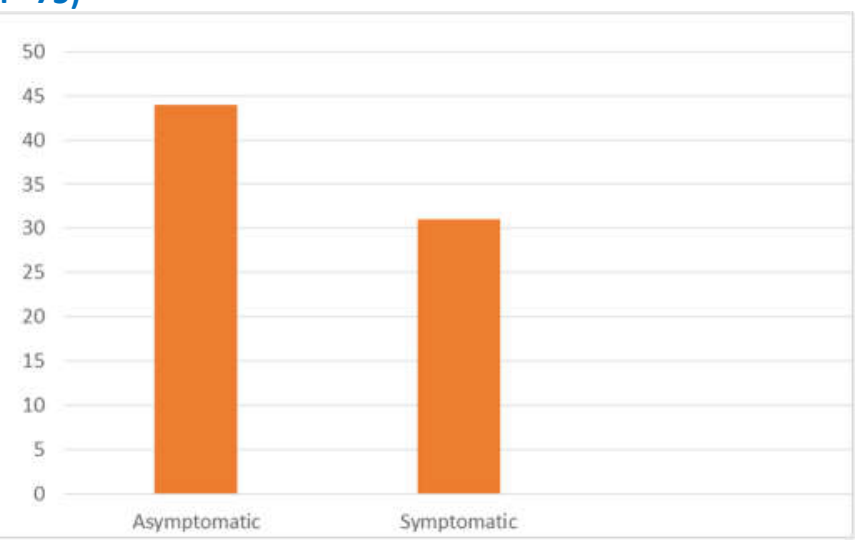

The duration of the symptoms ranged from two months to three years (median $=8$ months). The initial presenting symptom for all 31(41\%) patients was expansion of the jaw bone, associated with pain in 22 cases and clinically, though $44(59 \%)$ of the lesions were diagnosed incidentally during routine dental examination.

Figure 3: Anatomical distribution of odontogenic keratocyst (n - 75)

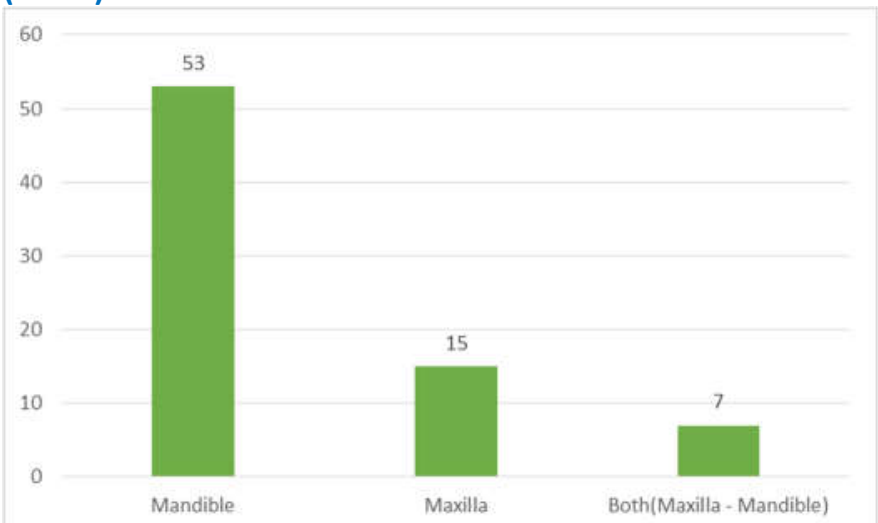

Table 2: Anatomical location and distribution of odontogenic keratocyst $(\mathbf{n}-75)$

\begin{tabular}{|l|l|l|l|}
\hline Mandible & \multicolumn{1}{|c|}{ Anterior } & Posterior & Total \\
\hline & $16(30.19 \%)$ & $37(69.81 \%)$ & $53(70.67 \%)$ \\
\hline Maxilla & & & \\
\hline & $3(20 \%)$ & $12(80 \%)$ & $15(20.00 \%)$ \\
\hline & & & \\
\hline Both & & & $7(9.33 \%)$ \\
\hline & & & $75(100 \%)$ \\
\hline Total & & & \\
\hline
\end{tabular}

The overall mandibular to maxilla ratio of tumors occurrence with $70.67 \%$ of the lesions located in the mandible, most frequently in the posterior region which included body angle ramus $69.81 \%$ and $30.19 \%$ in the anterior region. Only $20 \%$ of the lesions occurred in the maxilla, most in the posterior region $80 \%$ maxillary sinuses, pterygopalatine fossa or floor of the nose. In $9.33 \%$ cases the tumors involved more than one anatomical area, both maxilla and mandible. However, some lesion crossed the midline from right lower second molar or premolar to left lower second molar or premolar of mandible.
Table 3: Radiological features of odontogenic keratocyst (n - 75)

\begin{tabular}{|l|l|l|}
\hline Radiological features & Patients & Percentages \\
\hline General appearence & & \\
\hline Unilocular & 53 & $70.66 \%$ \\
\hline Multilocular & 22 & $29.33 \%$ \\
\hline & & \\
\hline Well defined & 72 & $96 \%$ \\
\hline Ill defined & 03 & $04 \%$ \\
\hline & & \\
\hline Radiolucent & 71 & $94.66 \%$ \\
\hline Radio Opaque & 00 & $00 \%$ \\
\hline Mixed type & 04 & $5.33 \%$ \\
\hline & & \\
\hline Effects on adjacent structure & & $37.38 \%$ \\
\hline Bone expansion & 28 & $30.00 \%$ \\
\hline Root resorption & 23 & \\
\hline Tooth displacement & & $36 \%$ \\
\hline $\begin{array}{l}\text { Tooth within the lesion } \\
\text { Impacted tooth }\end{array}$ & 27 & \\
\hline
\end{tabular}

Radiologically, $70.66 \%$ of the tumours were identified as unilocular lesions whereas $29.33 \%$ had a multilocular appearance. $96 \%$ were well defined and $04 \%$ were ill defined borders and $94.66 \%$ tumours were radiolucent area and $5.33 \%$ are mixed type lesions. Bone expansion were seen on $37.38 \%$, root resorption were seen on $30.00 \%$ and $36 \%$ were associated with an impacted or semi-impacted tooth. The majority of the lesions $82 \%$ were located in tooth-bearing areas, most commonly in a periapical zone $74 \%$.

All of the pathological reports reveals a similar histological features. The lesion consist of a fibrous connective tissue wall which contain islands of epithelium shows a small cystic lesion - Daughter cyst. The epithelial lining is highly characteristic and is composed of a parakeratin surface which is usually corrugated, a uniformity of thickness, generally between 4 to 10 cells in depth without rete peg and a palisaded basal layer of cells. The lumen of the cyst may be filled a thin strawcolored fluid or with a thicker creamy material. Sometimes, the lumen contains a great deal of keratin. Cholesterol and hyaline bodies at the site of inflammation may also be present. In our study most of the histopathological varites were orthokeratocyst and parakeratocyst, sometimes both were present.

Table 5: Treatment options of odontogenic keratocyst (n-75)

\begin{tabular}{|l|l|l|}
\hline \multicolumn{1}{|c|}{ Treatment } & Patients & Percentages \\
\hline & & \\
\hline Enucleation \& curatage & 09 & $12 \%$ \\
\hline Enucleation, curettage \& peripheral ostectomy & 22 & $29.33 \%$ \\
\hline Dreaging method & 39 & $52 \%$ \\
\hline Resection \& reconstruction & 05 & $6.67 \%$ \\
\hline & & \\
\hline Total & 75 & $100 \%$ \\
\hline
\end{tabular}


All these lesions were treated with varying surgical modalities. These includes enucleation, enucleation, curettage and peripheral ostectomy to aggressive treatments such as resection. $09(12 \%)$ patients were treated with enucleation and curettage, 22(29.33\%) cases received enucleation, curettage \& peripheral ostectomy, 39(52\%) patients were treated with Dredging method and 05 (6.67\%) cases were treated with segmental resection and autologous bone was used to reconstruct bone defects; in 1 cases with an iliac crest bone graft and 04 patient a micro vascularized fibula flap was employed to reconstruct an important tumours defect.

The average follow-up period was 5 years. The recurrences were usually diagnosed during the first 5 years postoperatively. Recurrence was found in 18 cases $(24 \%)$. Recurrences were observed in the posterior maxilla and mandible $(40 \%$ and $21.4 \%$ respectively) as compared to anterior maxilla and mandible $(16.7 \%$ and $15.4 \%$ respectively).The age distribution at recurrence was similar to the primary cases - showing a peak in the $2^{\text {nd }}$ decade to $3^{\text {rd }}$ decade.

Treatment of recurrence in our study were enucleation with curettage or peripheral ostectomy (6/18), surgical resection and reconstruction with reconstruction plate (4/18) and microvascular fibula graft $(8 / 18)$.

\section{Discussion}

The odontogenic keratocyst was first described by Philipsen in 1956 and designate an odontogenic keratocyst with a parakeratinized epithelial surface ${ }^{2}$ but its characteristics features was first described by Pindborg and Hansen in 1963. In 1967, Toller suggested that odontogenic keratocyst may be regarded as a benign neoplasm rather than a conventional cyst based on its clinical behaviour. ${ }^{4}$

The odontogenic keratocyst is now designated by the World Health Organization (WHO) as a keratocystic odontogenic tumour (KCOT) and is defined as a benign unicystic or multicystic, intraosseous tumour of odontogenic origin with a characteristic lining of parakeratinized stratified squamous epithelium and potential for aggressive, infiltrative behaviour. ${ }^{6}$ WHO proposed the terminology as keratocystic odontogenic tumor (KCOT) as it shows neoplastic nature. However In 2017, the new WHO classification of Head and Neck pathology retermed into the cystic category. ${ }^{4}$

Odontogenic keratocyst is so named because keratin is produced by the cystic lining. It is a Parakeratin lined cyst like lesion within bone. Odontogenic keratocyst is the one of the rare and distinctive developmental odontogenic cyst which from the dental lamina, containing clear fluid and a cheesy material resembling keratin debris. ${ }^{4}$

The age of distribution of odontogenic keratocyst in this study was $27.69 \pm 13.35$ years which ranged from 11 to 66 years and peak incidence $2^{\text {nd }}$ to $4^{\text {th }}$ decade; which is comparable with international literature, with a peak incidence in 3rd and 4th decade. Blanas and colleagues ${ }^{7}$ demonstrated the peak incidence in 4th and 5th decade. Odontogenic keratocysts are rare in extremes of age, under 10 and above 70 in our study.
However, Neville et al. ${ }^{8}$ reported in study conducted on 18 cases of odontogenic keratocyst a mean age of 69.9 years, which is much higher than for odontogenic keratocyst.

The distribution between sexes varies from equality to a male to female ratio of $1.6: 1$, except in children ${ }^{9}$ concerning the sex distribution, the present investigation showed that males were affected more than females. A similar male predominance also reported by Nohl and Gulabivala ${ }^{10}$ and Neville et al. ${ }^{8}$ Odontogenic keratocysts may occur in any part of the maxilla and mandible. ${ }^{8}$ Its predominantly affect the mandible especially posterior mandible including body, angle and ramus region (60-80\%). ${ }^{11}$ Regarding the site distribution, odontogenic keratocyst in our study occurs predominantly in the mandibular posterior region $37(69.81 \%)$. These finding confirmed by previous studies. ${ }^{12,13}$ Odontogenic keratocysts although tends to grow in medullary spaces without significant bony expansion but it can cause extensive bone destruction. ${ }^{14}$ This lesion can be associated, although not in all cases, with an impacted third molar. ${ }^{8}$ In our study bone expansion were seen on $37.38 \%$, root resorption were seen on $30.00 \%$ and $36 \%$ were associated with an impacted or semi-impacted tooth.

Neville et al. ${ }^{8}$ reports 18 cases of odontogenic keratocyst occur in anterior midline of the maxilla, Moreover, in our study, some cases of odontogenic keratocyst crossed the midline and only in 1 case the lesion involved the maxillary antrum. High incidence of maxillary antrum involvement was reported by Meara et al. ${ }^{13}$ which was not seen in our study. Clinically, an odontogenic keratocyst is characterized by aggressive, local growth. The lesion may manifest with pain, swelling, discharge, and occasionally parasthesia or displacement of teeth. ${ }^{15}$ Our finding is the same, in which the majority of the cases were seen in advanced stages, pain reported in 22 cases (29.33\%), and clinically $44(59 \%)$ of the lesions were diagnosed incidentally during routine dental examination while tooth displacement and parasthesia were observed in some cases. The expansion of the cyst is very minimal in the initial stage and it is due to the classical characteristic of the cyst to grow in anteroposterior direction in the medullary space of the bone. Expansion of buccal cortex in $30 \%$ of maxillary and $50 \%$ of mandibular regions. ${ }^{16,17,18}$ which was comparable to our study.
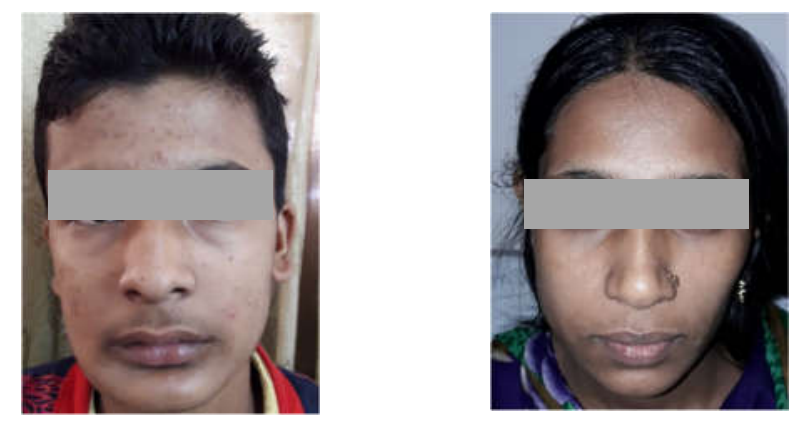

Figure - $1 \&$ 2: Facial asymmetry and swelling was not seen on both side of face. 

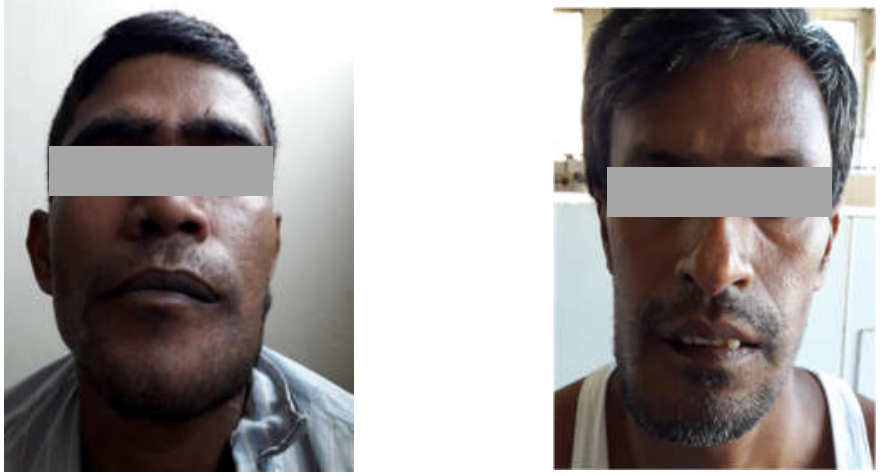

Figure -3 \& 4: Facial asymmetry and swelling was seen on left side of mandible (Fig 3) and right side of mandible (Fig 4)

Radiographically odontogenic keratocyst presents as well defined unilocular or multilocular (25-40\%) radiolucent lesion with smooth margin (corticated margin in secondarily infected cases), displacement of adjacent teeth without root resorption, lesion may contain impacted tooth (25-40\%), Expansion of cortical plates (buccal > lingual) with or without perforation. Cyst grows in medullary spaces of bone in anteroposterior direction, so bony expansion is minimal in initial stages. ${ }^{11,16,19}$

This finding is supported by our series, in which the lesion shows $70.66 \%$ were identified as unilocular lesions whereas $29.33 \%$ had a multilocular appearance. $96 \%$ were well defined and $04 \%$ were ill defined borders and $94.66 \%$ were radiolucent area and $5.33 \%$ are mixed type lesions. However, the prevalence of association with an unerupted tooth were $36 \%$, and root resorption in $30 \%$ and bone expansion was $37.38 \%$. Moreover, Struthers and Shear ${ }^{20}$ reported that the root resorption by odontogenic keratocyst appears to be very rare in comparison with that associated with dentigerous cyst which was comparable to our study. (Fig: 5 - 11)

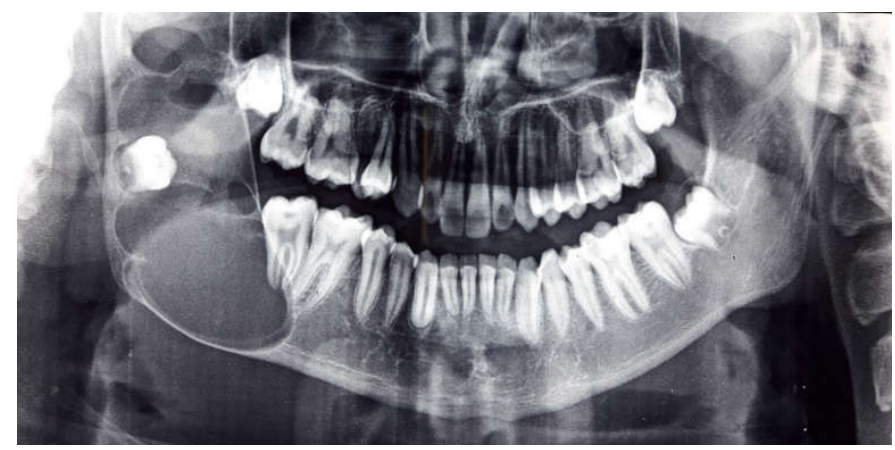

Figure 5: Panoramic view of the OKC located at the right mandibular ascending ramus with a multilocular appearance. Mandibular third molar tooth within the lesion.

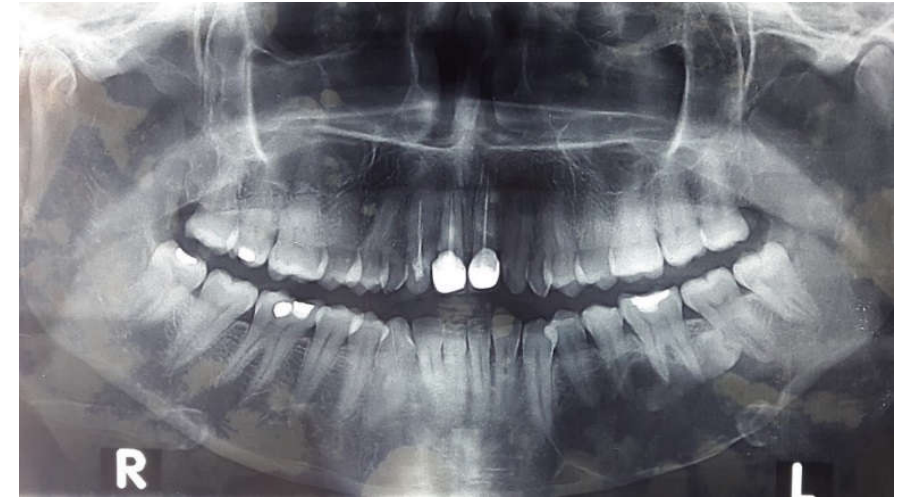

Figure 6: Panoramic view of the OKC located at the left mandibular ascending ramus with a unilocular appearance.

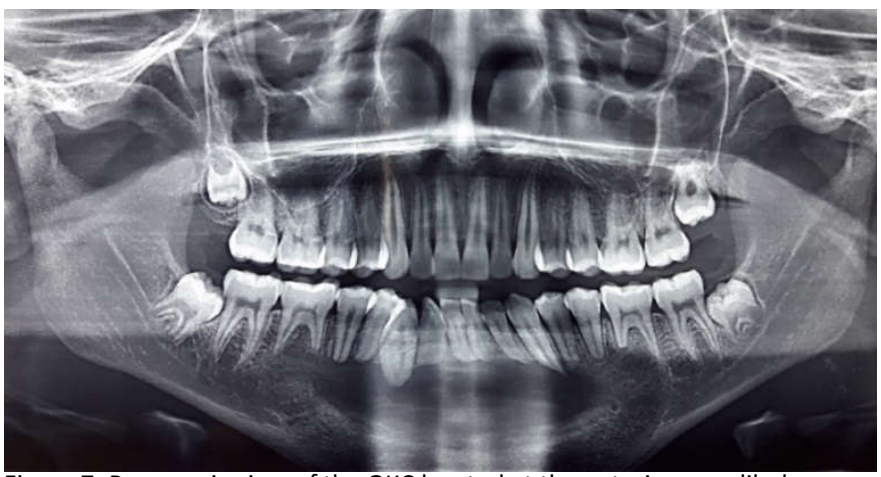

Figure 7: Panoramic view of the OKC located at the anterior mandibular region with a unilocular well defined appearance. Root resorption are also marked.

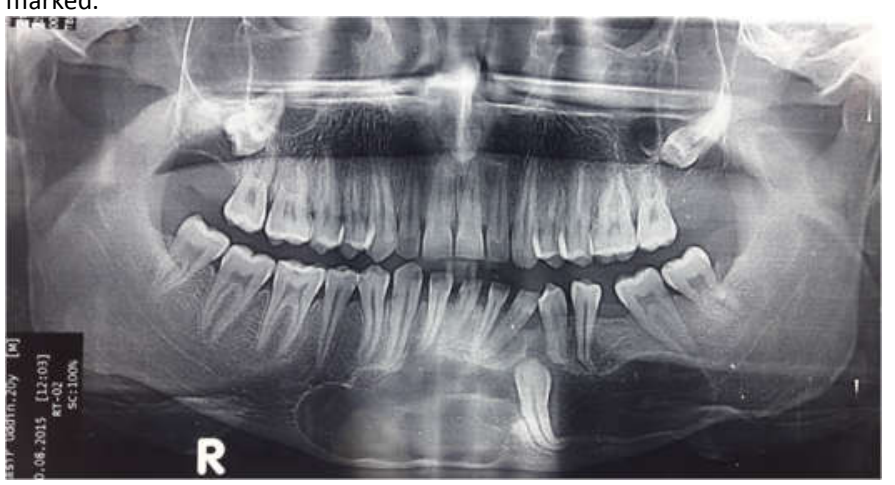

Figure 8: Panoramic view of the OKC located at the right mandibular ascending ramus anterior mandibular region with a multilocular appearance and scalloped border. Mandibular canine tooth within the lesion.

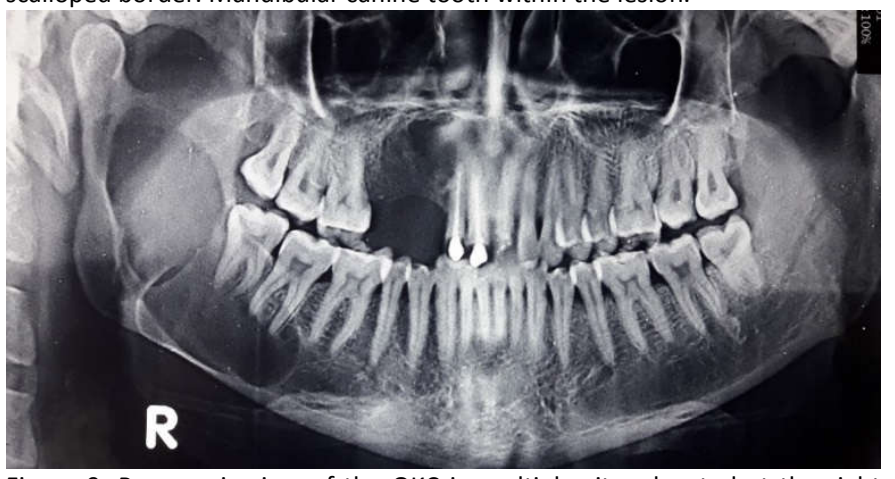

Figure 9: Panoramic view of the OKC in multiple site - located at the right mandibular ascending ramus region and right maxilla with a unilocular appearance. 


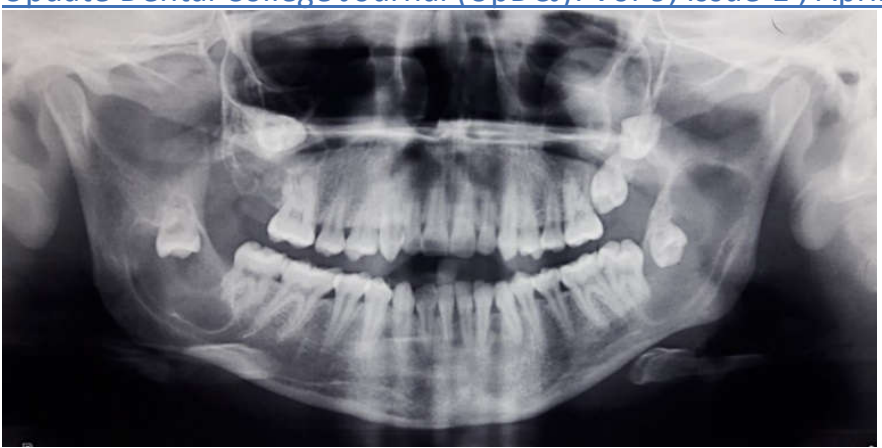

Figure 10: Panoramic view of the OKC located on both side of mandibular ascending ramus with a multilocular appearance and impacted third molar seen on the both side within the lesion.

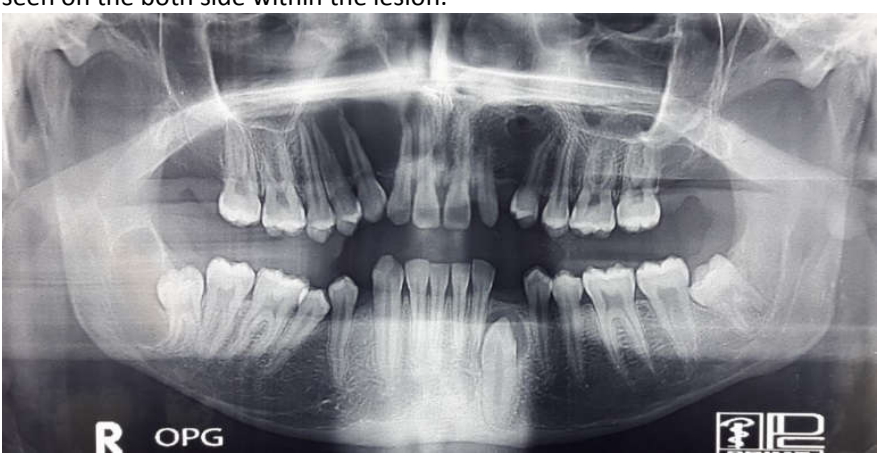

Figure 11: Panoramic view of the OKC located on both side of mandible - right ascending ramus and left canine region with a unilocular appearance and impacted third molar seen on the right side and impacted canine in the left

side within the lesion.

Histologically, in 1992 (WHO) designated two different variants of odontogenic keratocyst, an orthokeratinized and a parakeratinized. The parakeratinized form consists in a basal layer made of cubic or cylindrical cells lacking acanthosis and rete ridge proliferation. It is covered by five to eight layers of squamous epithelium lining. The epithelium is characterized by a wavy or corrugated parakeratinized surface layer. Some signs of dysplasia may be observed. The basal layer of the tumour might be budding into the supporting connective tissue, forming daughter cysts at the periphery. If inflammation occurs, the fibrous capsule in the wall of the connective tissue thickens. In addition, it may cause ulceration of the epithelium, which acquires well-developed ridges, whereas the keratinization tends to disappear. This capsule can contain dystrophic calcifications or small fragments of cartilage of unknown origin. ${ }^{21}$ Orthokeratinized odontogenic cyst does not show pallisading of basal cells and is histologically different from parakeratinized form showing less aggressive behavior and destruction. ${ }^{22,23}$ The histopathological features of odontogenic keratocysts in our study were comparable with those seen elsewhere. ${ }^{24,25}$

Different surgical techniques have been suggested for the treatment of odontogenic keratocysts and the most appropriate treatment remains a subject of controversy. Treatments are generally classified as conservative and aggressive such as surgical resection. ${ }^{8}$ Conservative treatment generally includes decompression or marsupialization, simple enucleation, with or without curettage, Aggressive treatment generally includes peripheral ostectomy, chemical curettage

13 | $\mathrm{P}$ a g e with carnoy's solution and surgical resection. ${ }^{8}$

Some surgeons believe that the OKC can be properly treated with enucleation if the lesion is removed intact. However, complete removal of the OKC can be difficult because of the thin, friable epithelial lining, limited surgical access, cortical perforation, skill and experience of the surgeon and the desire to preserve adjacent vital structures. ${ }^{8}$

Aggressive treatment, such as ostectomy is necessary in cases associated with soft tissue invasion, a multi recurrent keratocyst, malignant transformation. ${ }^{2}$ Peripheral ostectomy should be used with caution as it may disperse microcysts embedded in peripheral bone to cause recurrence. ${ }^{11}$ In our study $09(12 \%)$ patients were treated with enucleation and curettage, 22(29.33\%) cases received enucleation, curettage \& peripheral ostectomy.(Fig 12-18)

Dredging Method is a conservative surgical procedure in which, after deflation and enucleation or only enucleation, repeated dredging is applied to accelerate new bone formation by removing out the scar tissue from the bony cavity. In this study most of the patient were under dredging method 39 (52\%) which is comparable to various study. ${ }^{26,27,28}$
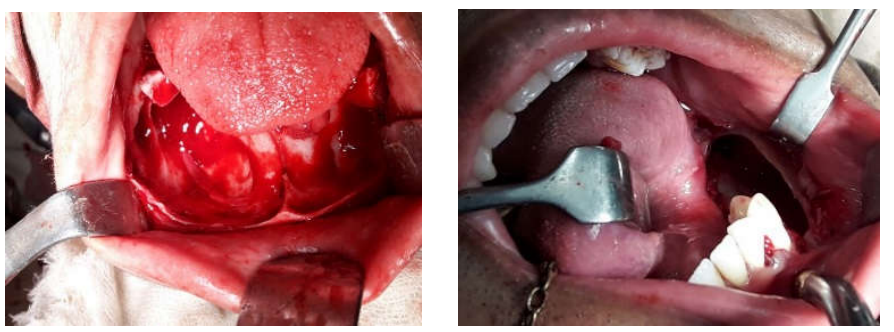

Figure 12: Enucleation of the lesion and peripheral ostectomy was done from right first molar to left first molar. Figure 13: Enucleation of the lesion and peripheral ostectomy was done from body angle and ramus of the left side of mandible
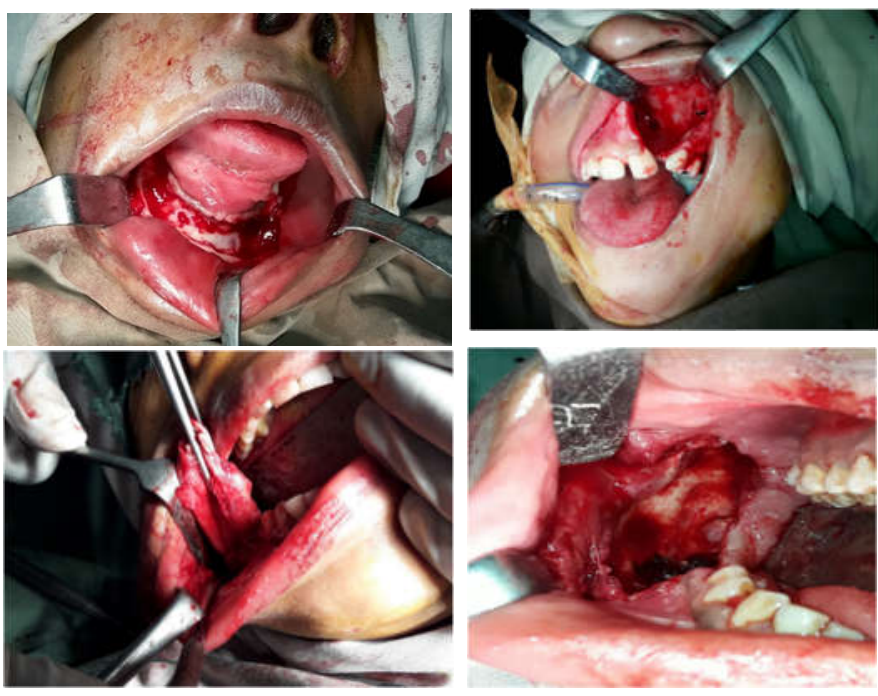

Figure 14: Enucleation of the lesion and peripheral ostectomy was done from right first molar to left first molar. Figure 15: Enucleation of the lesion and peripheral ostectomy was done in left maxilla. Figure 16. Enucleation of the lesion from right mandible involving body angle and ramus region. Figure 17: Peroperative intraoral view of the patient. After enucleation of the lesion from right mandible involving body angle and ramus region.

Website: https://www.banglajol.info/index.php/UpDC 

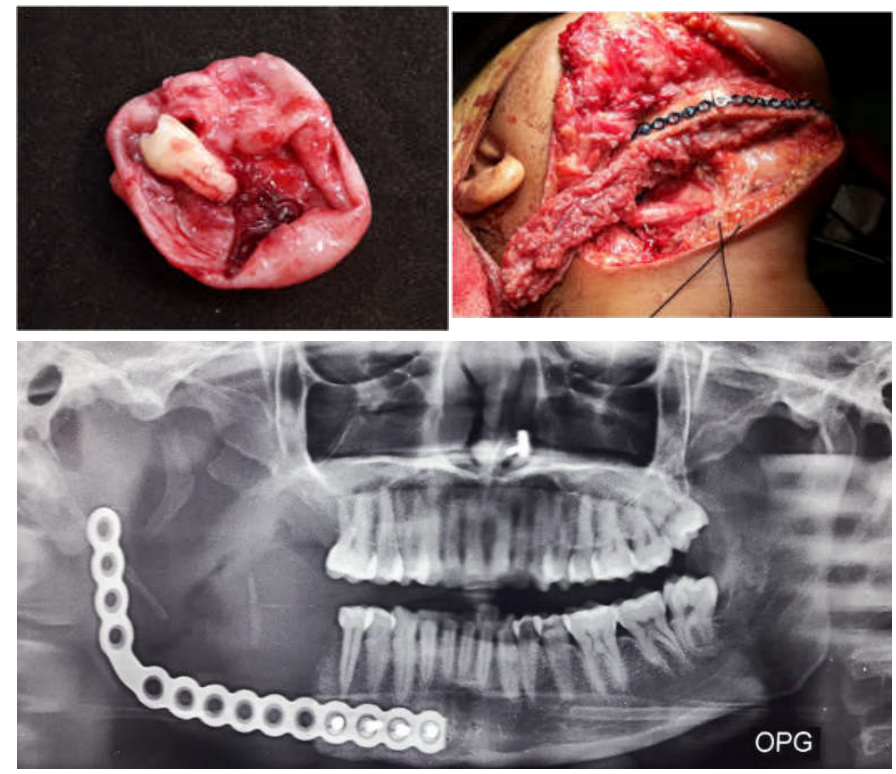

Figure 18. After enucleation of the lesion Figure 19: Reconstruction was done by reconstruction plate after surgical resection. Figure 20: Reconstruction was done by microvascular fibula bone graft after surgical resection.

According to Blanas and colleagues; William and Conner resection was recommended to be the best treatment of choice only in cases of recurrence (3 or more times), in very large and aggressive lesion, in cases of insufficient residual cortical bone or extensive soft tissue involvement. ${ }^{7,} 29$ Segmental resection offers a high cure rate but produces significant morbidity such as loss of jaw continuity, facial disfigurement and need for reconstruction.In this study 05 (6.67\%) cases were treated with segmental resection and autologous bone was used to reconstruct bone defects; in 1 cases with an iliac crest bone graft and 04 patient was reconstructed by micro vascularized fibula flap.(Fig 20)

Higher recurrence rate has been documented with conservative procedures such as marsupialization and enucleation of the lesion and recurrence rate is relatively low with aggressive treatment. ${ }^{30}$

The topography of the lesion seems to be a recurrence risk factor. The angle and ramus lesions are more recurrent due to difficulty of access during enucleation, mainly for the multilocular forms ${ }^{31}$ which was comparable to our study. In our series, however, all the lesions with tooth involvement were treated with tooth extraction or apicectomy and this treatment appears to be related with recurrence. Treatment of recurrence in our study were enucleation with curettage or peripheral ostectomy (6/18), surgical resection and reconstruction with reconstruction plate (4/18) and microvascular fibula graft (8/18).

Recurrence rate varies from 2.5 to $62.5 \%$ with much literature suggesting approximately 30\%. ${ }^{1,11,22}$ Auluck and Pai demonstrated $38 \%$ recurrence ${ }^{3}$ and Brannon depicted $32.5 \%$ recurrence. $^{1}$ after surgical cure of OKCs. In this study, recurrence occurred in 18 patients with recurrence rate of 24 $\%$. Recurrence has been described up to 10 years after treatment, though it is more common during the first 5-7 years
32 which was comparable to our study. Conclusion:

Odontogenic keratocyst is an aggressive cyst, male predominant, posterior mandible is the commonest site, welldefined unilocular radiolucency are commonest radiological feature. Treatment options should be decided by the surgeon according to the clinical and hislological feature.Radical treatment options such as resection or marginal resection reduced the recurrences of the tumour but higher morbidity and jaw deformity. Comparatively, conservative treatment options such as dredging methods might be the treatment of choice due to preservation of normal anatomical structure like tooth germs and bone. A long term follow up is paramount importance for the research and understanding the clinical pattern, behavior, treatment and recurrence of the lesion.

\section{References:}

1. Brannon RB. The odontogenic Keratocyst. A clinicopathological study of 312 cases. Part I. Clinical features. Oral Surg Orgal Med Oral Pathol Oral Radiol Endod 1976; 42: 54-72. https://doi.org/10.1016/0030-4220(76)90031-1

2. Belkacem Raouâa, Sioud Samèh, Touil Dorsaf, Ayachi Rahma, Selmi Jamil Recurrence challenge in odontogenic keratocyst variants,two clinical cases

3. Auluck A, Pai KM. Treatment of recurrent odontogenic keratocyst: a known but forgotten point. Br J Oral Maxillofac Surg 2006; 44: 74-75. https://doi.org/10.1016/j.bjoms.2005.03.027 PMid:15946778

4. Passi D, Singhal D et al. 2017. Odontogenic Keratocyst (OKC) or Keratocystic Odontogenic Tumor (KCOT) - journey of OKC from cyst to tumor to cyst again: Comprehensive review with recent updates on who classification (2017) 2017, International Journal of Current Research, 9, (07), 54080-54086.

5. Kolokythas A, Fernandes RP, Pazok. A. Odontogenic Keratocyst: To decompress or not to decompress? A comparative study of decompression and enucleation versus resection/peripheral ostectomy. J Oral Maxillofac Surg 2007; 65: 640-44. https://doi.org/10.1016/i.joms.2006.06.284 PMid:17368357

6. Barnes L, Eveson JW, Reichart P, Sidransky D, editors. Pathology and genetics of head and neck tumours. Lyon: IARC Press; 2005. WHO classification of tumours series.

7. Blanas N, Freund B, Schwartz M, Furst IM. Systemic review of treatment and prognosis of odontogenic keratocyst. Oral Surg Oral Med Oral Pathol Oral Radiol Endod 2000; 90: 553-58.

https://doi.org/10.1067/moe.2000.110814 PMid:11077375

8. Neville BW, Damm DD, Brock T. Odontogenic Keratocyst of the midline maxillary region. J Oral Maxillofac Surg 1997; 55:340-4 (Midline). https://doi.org/10.1016/S0278-2391(97)90121-X

9. SINGH M, GUPTA KC. Surgical treatment of odontogenic keratocyst by enucleation. Contemporary Clinical Dentistry. Oct-Dec 2010 ,Vol 1, Issue 4

10. Nohl FSA, Gulabivala K. Odontogenic Keratocyst as periradicular radiolucency in the anterior mandible. Oral surg Oral Med Oral Pathol 1996; 81: 103-9. https://doi.org/10.1016/S1079-2104(96)80157-0

11. Chirapathomsakul D, Jansisyanant P, Sastravaha P. A review of odontogenic reratocysts and behaviour of recurrences. Oral Surg Oral Med Oral Pathol Oral Radiol Endod 2006; 101: 05-09. https://doi.org/10.1016/j.tripleo.2005.03.023 PMid:16360602

12. Eliasson $S$, Isacsson $G$, Kondell PA. Lateral periodontal cysts: clinical, radiographical, and histopathological findings. Int J Oral Maxillofac Surg 1989; 18:191-3. https://doi.org/10.1016/S0901-5027(89)80048-7

13. Meara JG, Shah S, Li KK, Gunningham MJ. The odontogenic Keratocyst: a 20-years clinicopathologic review. Laryngoscope 1998; 2:280-3. https://doi.org/10.1097/00005537-199802000-00022

Website: https://www.banglajol.info/index.php/UpDCJ 
14. Chang NJ, Shyu V, Chen $\mathrm{CH}$. Maxillary reconstruction for a huge odontogenic keratocyst. J Craniofac Surg 2011; 22:1165-67. https://doi.org/10.1097/SCS.0b013e318210bb95 PMid:21586981

15. Ahlfors E, Larsson A, Sjogren S. The Odontogenic Keratocyst: A benign cystic tumor? J Oral Maxillofac Surg 1984; 42:10-19. https://doi.org/10.1016/0278-2391(84)90390-2

16. Philipsen HP. Keratocystic odontogenic tumor. Barnes L, Eveson JW, Reichart PA, Sidransky D, eds. 2005. World Health Organization Classification of Tumours: Pathology and Genetics Head and Neck Tumours. Lyon, France: IARC Press; 306-7.

17. Hyun HK, Hong SD, Kim JW. 2009. Recurrent keratocystic odontogenic tumor in the mandible: a case report and literature review. Oral Surg Oral Med Oral Pathol Oral Radiol Endod., Aug. 108(2):e7-10. (Medline).

18. Donoff RB, Harper E, Guralnick WC. 1972. Collagenolytic activity in keratocysts. J Oral Surg. Dec. 30(12):879- 84. (Medline).

19. Sciubba JJ, Fantasia JE, Kahn LB, eds. 1999. Atlas of Tumor Pathology: Tumors and Cysts of the Jaw. 3rd ed. Washington, DC: Armed Forces Institute of Pathology, 34-40.

20. Struthers $P$, Shear M. Root resorption by ameloblastoma and cysts of the jaws. Int J Oral Surg 1976; 5:128-32. https://doi.org/10.1016/S0300-9785(76)80061-0

21. Ruhin-Poncet B, Picard A, Martin-Duverneuil N, Albertini AF, Goudot P. Kératokystes (ou tumeurs odontogéniques kératokystiques). Rev Stomatol Chir Maxillofac 2011112:87-92. https://doi.org/10.1016/j.stomax.2011.01.010

22. Neville BW, Damm DD, Allen CM, Bouquot JE. Oral and maxillofacial pathology 2nd ed. Philadelphia: Saunders; 2002. p. 595.

23. Arnnop P. Management of odontogenic keratocysts of the jaws. A 10 year experience with 120 consecutive lesions. J Craniomaxillofac Surg 2009; 10: 10-16.

24. Shafer WG, Hine MK, Levy BM. A textbook of oral pathology, 4th ed, Philadelphia: WB Saunders Co, 1983:269-73.

25. Mohammad A, Ronald AB. Maxillary odontogenic cyst. A common and serious clinical misdiagnosis. J Am Dent Assoc 2003; 134(7):877-883.

26. SMA Sadat, M Ahmed. Dredging Method - A Conservative Surgical Approach for the Treatment of Ameloblastoma of Jaw. Journal of Bangladesh College of Physicians and Surgeons. Vol. 29, No. 2, April 2011 https://doi.org/10.3329/jbcps.v29i2.7951

27. Dredging Method: an alternative approach for treatment of ameloblastoma. I. Haider. M. Ahmed. International Journal of Oral and Maxillofacial Surgery 44(1):e221 • October 2015 https://doi.org/10.1016/j.ijom.2015.08.113 https://doi.org/10.1016/i.ijom.2015.08.113

28. Conservative Management of Keratocystic Odontogenic Tumors of Jaws. Nurhan Güler, Kemal Şençift, and Özge Demirkol. ScientificWorld Journal. 2012; 2012: 680397

29. Williams TP, Conner Jr FA. Surgical management of odontogenic keratocyst: aggressive approach. J Oral Maxillofac Surg 1994; 52: 964-66. https://doi.org/10.1016/S0278-2391(10)80081-3

30. Teresa MA, Christopher BC. A retrospective review of treatment of the odontogenic keratocyst. J Oral Maxillofac Surg. 2005; 63:635-9. https://doi.org/10.1016/j.joms.2004.07.026 PMid:15883937

31. Chemli H, Dhouib M, Karray F, Abdelmoula M. Les facteurs de risque de récidive des Kératokystes odontogéniques des maxillaires. Rev Stomatol Chir Maxillofac 2010; 111:189-192.

https://doi.org/10.1016/j.stomax.2009.07.011 PMid:20553889

32. Sánchez-Burgos R, González-Martín-Moro J, Pérez-Fernández E, Burgue-o-García M. J Clinical, radiological and therapeutic features of keratocystic odontogenic tumours: a study over a decade. Clin Exp Dent. 2014; 6(3):e259-64.https://doi.org/10.4317/jced.51408

PMid:25136427 PMCid:PMC4134855 